\title{
Learners' Problem in Phonetics with the Intelligibility at Segmental and Supra-segmental Level
}

\author{
Md Nurul Anwar \\ BGMEA University of Fashion and Technology, Dhaka, Bangladesh
}

\begin{abstract}
Bengali, though not much discussed, is one of the most resourceful Indo-Aryan languages. Its fortynine letters allow its speakers utmost flexibility to diphthongize and to form wide ranges of consonant cluster in accordance with the demand of spelling and meaning. Remarkably enough, Bengali has more sounds than needed to facilitate any English sounds without making any distortions to them. But, in fact, there are very many pronunciation varieties people are used to pronouncing Bengali words: most sounds they may bring into their English often can be variably ${ }^{1}$ attributed to their own regional dialects rather than the standard CholitaBhasha ${ }^{2}$. However, apart from the local dialects, Cholita Bhasha speakers are likely to make distortions in the production of certain English sounds, but incontestably not in too many. This paper looks into the similarities and dissimilarities between English and Bengali at segmental and supra-segmental level and attempts to pinpoint the influences behind these distortions to rectify learners' errors init.
\end{abstract}

Index Terms - Cholita Bhasha, segmental, supra-segmental, consonant clusters

\section{INTRODUCTION}

"Within the contrastive analysis framework, the word interference is used to refer to a reflection of the surfacestructure discrepancies between L1 and L2"' (James, 1980, p. 175).

The statement mentioned above is not pragmatic enough to serve a direct link to the analysis of phonetics and phonology though it shows the shallowness of the term contrastive analysis, but it can be used as a tribute to Lado and it is surely a matter of positivity that chapters and articles are still composed in the field of contrastive phonology. Apart from this, contrastive analysis in general refers to a way of comparing and contrasting various linguistic features of two languages; for example, sound systems, grammatical structures, vocabulary systems, writing systems and above all cultural aspects of two languages. Results from contrastive analysis are valid and can be accepted but there are difficulties in interpreting this CA hypothesis in relation to learners' behaviors (Gass \& Selinker, 1994, p.17). The mention of the phrase learners' behavior is powerful enough to relate itself with the study of all other aspects of language including phonology.

\section{Methodology}

Problem with intelligibility at segmental and supra segmental level has been there ever since though the discussion on this has been very rare. The nature of this research demands close attention to the production of nuances in phonemes at different levels of articulation. In or der to observe closely the distinctions and distortions made by Bengali speakers, which can be labelled as same in case of other non-native speakers, this research adopts a thorough empirical study using quantitative method as it can give the hands-on result at the micro level analysis on any pronunciation production. The major tool used in this research was the selection of subjects in terms of their background and setting. Data was collected from local markets and other regions where it can be possible to acquire authentic data. After the collection of data, a dichotomy was set between the male and female respondents in terms of the variables found. Then, the survey data was put on tables to mark them as distinct from each other. Next, the data was processed through different graphs to analyze and find out the percentage. Now, a decision was made in connection with the problems, distortions and replacements made by the speakers at different segments of the given words. At the end, the result was displayed on graphs with appropriate selections and differences, which demonstrates a clear picture of the result.

\section{DISCUSSION}

\section{PROBLEMATICS OF CONTRASTIVE ANALYSIS}

\footnotetext{
${ }^{1}$ Bangladesh has plenty of dialects and every dialect is distinctive in individual features. This dialectic L1 often has direct influence on L2 sounds. This dialectic interference varies widely from place to place and some people have privilege in their L2 pronunciation as their dialect is phonologically approximant.

${ }^{2}$ The regional dialect of Chittagong which significantly shares equivalence with the English sounds.
} 
The limitation of contrastive analysis has to be mentioned to avoid any drawbacks in this research albeit this discussion seems irrelevant. On the contrary, this discussion falls back on the aim of this research that it embraces some aspects of the successive discussion to come in. In their critique Gass and Selinker have claimed that contrastive analysis is built upon a prediction on a data collected from some learners' utterances of certain behavior at a certain time, which does not provide proper interpretation and analysis for second language learners, for instance:

An English-speaking learner of Italian tends to devoice the first member of the clusters /zmzn,zl/, and then adjust them to the English clusters /smsnsl/. Thus, the CA hypothesis predicts learners' behaviors depending on some observational data of some learners under certain unspecified conditions (1994, p. 2).

Despite the limitation they believe that contrastive analysis is vital to discuss any range of interchangeability between the linguistic features between interlanguage (Gass\&Selinker, 1994, p. 3).

\section{Bengali Speakers' English Pronunciation: Problems in Segamenal And Supra-Segmental LeVel}

\section{Near similar sounds}

There can be apparent influence of L1 on L2 in the production of pronunciation of L2. There are articulatory similarities between English and Bangla, but on occasions where some Bangla sounds are unlike English require the speakers to swap their articulators to fit the production of L2, English. In this case, the nearer the articulation system of L1 to L2 the more replacement of L2 sounds with L1 is manifest. These subtle differences yield different languages such as Chinglish, Indian English, Banglish and so on. A few phonemes (consonants) in English resembles to some extent to some sounds in Bengali, but they involve different places of articulation. For example, English contains labiodental sounds such as /f/ and /v/ whereas Bengali contain the bilabial stops $/ \mathrm{p}^{\mathrm{h}} /$ and $/ \mathrm{b}^{\mathrm{h}} /$ which are pronounced with much stress than regular English fricatives. Hence, the words pronounced with these two sounds sound as stressed and aspirated bilabial plosives rather than English fricatives, /f/ or /v/. Some examples can be given from the Bengali speakers' speech; for example, words like fashion, vegetables, fishing etc. Therefore, native English speakers may well confuse these words as aspirated $/ \mathrm{p}^{\mathrm{h}} /$ and $/ \mathrm{b}^{\mathrm{h}} /$.

For English sounds with different stress level like $/ z / / d z /$ and $/ 3 /$ are quite different from their Bengali equivalents. For example, Bengali has no sounds similar to /dz/, and all sounds in this category are pronounced with same stress and follows the same articulation; however, they differ not in terms of sounds but in terms of their word formation. For instance, words in Bengali containing/z/ sound is different in meaning than a word made up of /dz/ sound with no difference occurring in their pronunciation in Bengali. A sound like / $/$ / very often gives problems to all types of learners at the beginner level. They cannot often make actual $/ 3 /$ sound in the word like 'television'. They pronounce this sound either close to $/ \mathrm{d} z /$ or near $/ \mathrm{J} /$. So, it also may create in all possibility toward English listeners in terms of intelligibility and vice versa.

\section{RESULTS AND ANALYSIS}

\section{A. Consonant Clusters}

Many word-initial consonantal clusters are simplified according to Bengali phonotactics. A common tendency is to use a short vowel sound before these initial consonantal clusters is visible among less educated people. They also have intelligibility problem with sound switching between /s/ and / / as well, for instance: Data collected and transcribed from local 50 Chittagonian (Bengali) speakers both male (25) and female adults (25) that show British pronunciation influenced by Bengali pronunciation is given below: (figure:1)

\begin{tabular}{|c|c|}
\hline English Pron. & Bengali \\
\hline Establish /istabli!/ & lijtabli/l \\
\hline Student /'stjudd(ə)nt/ & /i $\int$ tudent/ \\
\hline station /'ste1/n/ & /1] tefon/ \\
\hline smell /smel/ & /1smel/ \\
\hline
\end{tabular}

Illustration of data and graph containing the percentage of pronunciation difference by male and female of the first word from the fig: 1 has been displayed below:

Speakers were asked to pronounce the following words:

\begin{tabular}{|c|c|c|c|c|c|}
\hline \multicolumn{6}{|c|}{ TABLE I } \\
\hline Establish & Male & Female & Transcription & Male & Female \\
\hline /ijtabli!/ & 3 & 2 & liftabli!/ & $3 \%$ & $2 \%$ \\
\hline /istablif/ & 47 & 48 & /istabli!/ & $47 \%$ & $48 \%$ \\
\hline
\end{tabular}




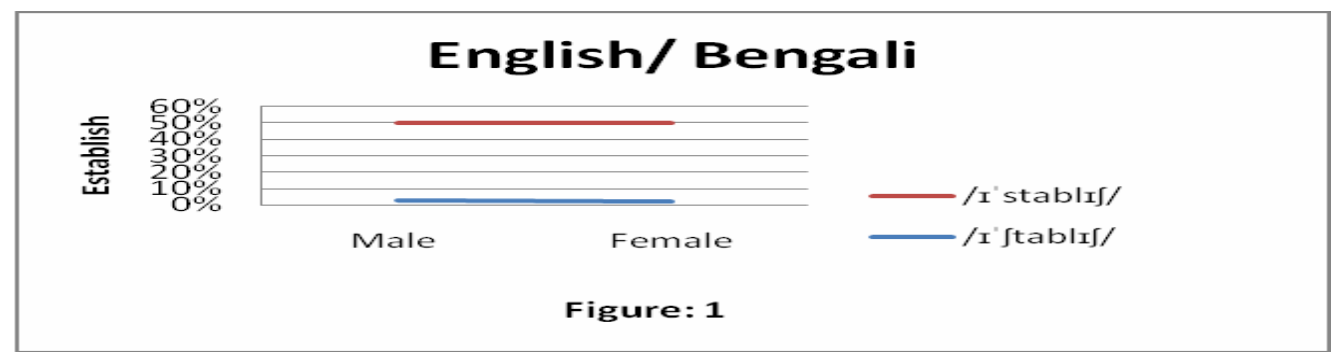

Findings: The above illustration demonstrates a vast difference between male and female who are able to duplicate British pronunciation and who cannot. It is proven that only $3 \%$ male and $2 \%$ female could come up with the proper pronunciation which is hugely marginalized by their inability to pronounce the word by $47 \%$ and $48 \%$. In the final clusters also, we can notice there is a propensity among the speakers of Bengali to pronounce according to spelling norm. The ordinary speakers would fail to distinguish between the affricates and fricatives, and this is one of the foremost difficulties they have in pronunciation, for instance, in the articulatory places of $/ \mathrm{t} / /$ and $/ \mathrm{s} /$. Here, they tend to replace/t $/$ with/s/. They often confuse/z/with/dz/which is different from Bengali similar sound. This mistake can be attributed to over-generalization too. Similar data collected from Bangladeshi Cholita Vasha speakers both male and female adults (100) that show the evidence of such generalization. Examples are shown below:

\begin{tabular}{|c|c|}
\hline \multicolumn{2}{|c|}{ TABLE II } \\
\hline Words (British RP) & Words in Bengali \\
\hline Chittagong / t fitəgon/ & /sitəgay/ \\
\hline Lecture /'lect]ə/ & /leksər/ \\
\hline National /'næenəl/ & /næenəl/ \\
\hline Change /t $\mathrm{jen}(\mathrm{d})_{3} /$ & $/ \operatorname{sen}(\mathrm{d})_{3} /$ \\
\hline General/dzenral/ & /zenaral/ \\
\hline
\end{tabular}

Illustration of the graph regarding figure-2 has been shown below:

\begin{tabular}{|c|c|c|c|c|c|}
\hline Chittagong & Male & Female & Transcription & Male & Female \\
\hline / t fitəgny/ & 7 & 4 & / t fitəgny/ & $7 \%$ & $4 \%$ \\
\hline /sitegay/ & 43 & 46 & /sitəgay/ & $43 \%$ & $46 \%$ \\
\hline
\end{tabular}

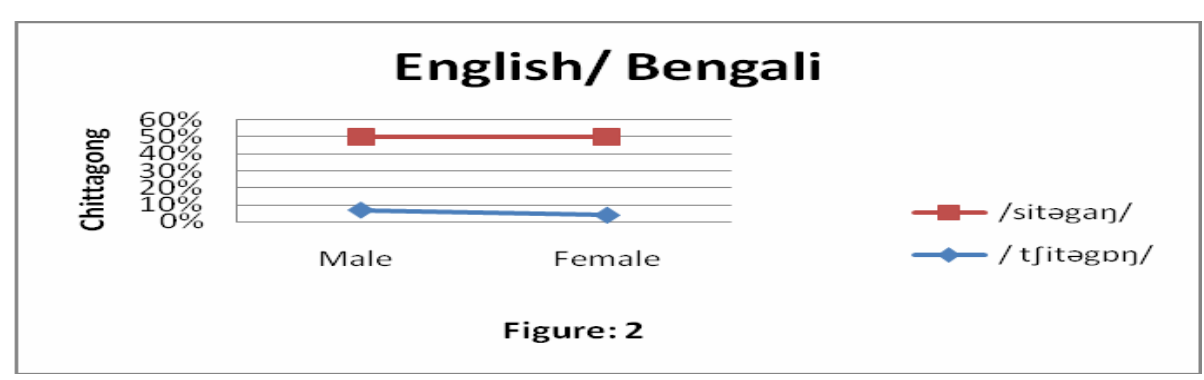

Findings: The above representation provides the evidence on the replacement of $/ \mathrm{t} \int /$ with $/ \mathrm{s} /$ by most Bengali speakers of English. It is seen that both male and female are equally incapable of pronouncing the word Chittagong with proper $/ \mathrm{t} \mathrm{J} /$ sound. There is a remarkable difference among male and female who can and cannot come up with the correct pronunciation without replacing $/ \mathrm{t} / \mathrm{f}$ with $/ \mathrm{s} /$. Only $7 \%$ male and $4 \%$ female are able to pronounce the word which is almost none to their counterparts $43 \%$ and $46 \%$.

\section{B. Rolling Articulation of Sound $/ r /$}

Bengali speakers who are not educated abroad like UK or USA would have rolling /r/ sound unlike RP or GAE which has a mild or an approximant /r/. Unlike GAE Bengali /r/ will require the tongue to touch alveolar and make a trill. The cardinal vowel /3:/ becomes broad /a/ in Bengali, for instance: (Data collected from 25 male and female at a 
local Bazar in Chittagong, commercial district of Bangladesh)

\begin{tabular}{|c|c|c|c|c|c|}
\hline $\begin{array}{l}\text { Words pronol } \\
\text { Driver/'driva } \\
\text { Person/'p3:sn } \\
\text { Capture/kept }\end{array}$ & $\mathrm{RP}$ & & & & \\
\hline Transcription & Male & Female & Transcription & Male & Female \\
\hline /driva/ & 3 & 1 & /driva/ & $12 \%$ & $4 \%$ \\
\hline /drivar/ & 22 & 24 & /drivar/ & $88 \%$ & $96 \%$ \\
\hline
\end{tabular}

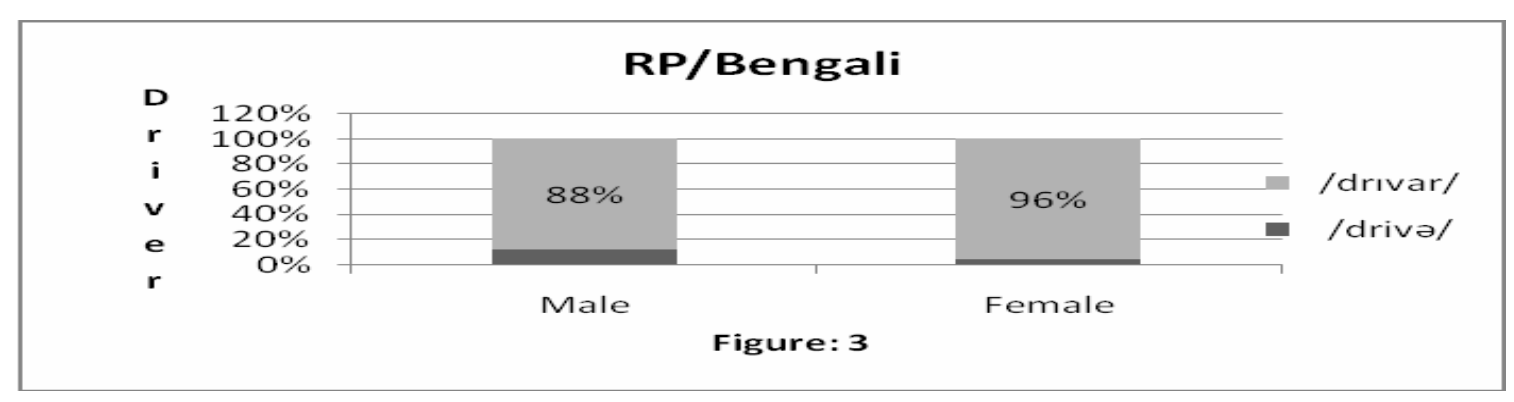

Findings: The above report from the survey shows the male and female pronouncing the given word with a more accented rolling /r/ like Indian speakers of English. 88\% male and 96\% female came up with rolling /r/ sound instead of a mild /r/ used by native speakers of English. Also, the cardinal vowel turns into a much voiced /a/. It can be anticipated that the problem can be overcome through regular practice with a native speaker of English.

\section{Stress in Words}

At the supra-segmental aspects, there is apparently no specific and regular word stress in Bengali like English which has certain stress syllables, and any stress apparent can be directly and variably identified with regional accents. However, the tendency to put stress on the first syllable is the most probable in this case with the distortion of diphthong sounds. The sample has been collected from local station in Chittagong. 60 people were interviewed and asked to pronounce words, Tour, pupil, carpenter, and cultural, which have later been transcribed into their RP and Bengali version as they uttered.

\begin{tabular}{|c|c|c|c|c|c|}
\hline In English & & & In $\mathrm{B}$ & & \\
\hline Tour /'tu:r/ & & & /tor & & \\
\hline Pupil/pjupl// & & & $/ \mathrm{pu}$ & & \\
\hline Carpenter /'ka:pentə / & & & $/ \mathrm{kar}$ & & \\
\hline 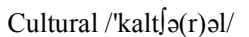 & & & $/ \mathrm{kal}$ & & \\
\hline Tour /Cultural & Male & Female & $\begin{array}{l}\text { Tour } \\
\text { /Cultural }\end{array}$ & Male & Female \\
\hline /'tu:r/ & 3 & 0 & /'tu:r/ & $5 \%$ & $0 \%$ \\
\hline /tor/ & 57 & 60 & /tor/ & $95 \%$ & $100 \%$ \\
\hline /'kaltfə(r)əl/ & 1 & 0 & /'kalt Jə(r)əl/ & $2 \%$ & $0 \%$ \\
\hline /kalsaral/ & 59 & 60 & /kalsaral/ & $98 \%$ & $100 \%$ \\
\hline
\end{tabular}

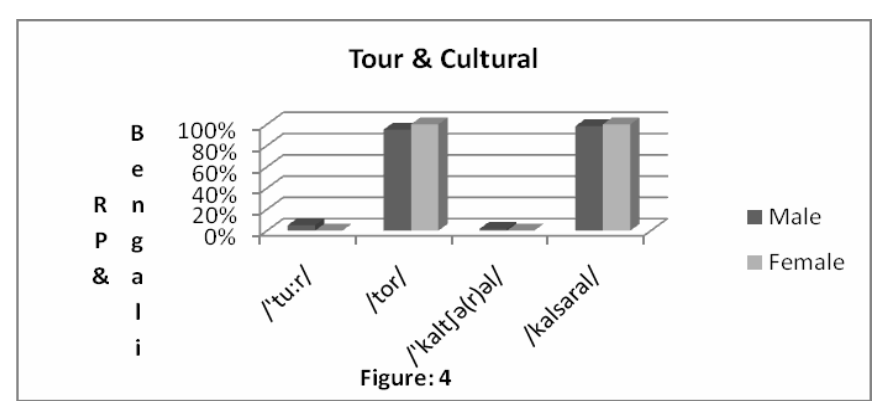


Findings: The graph shows a majority $95 \%$ and $98 \%$ Male interview pronounce the word tour and cultural wrong having difficulty to put stress on the proper syllable. They also demonstrate a failure to pronounce the fricative/t $\mathrm{f} / \mathrm{which}$ is replaced by /s/ sound. In case of female, the percentage is even more depressing. It means most speakers tend to go for more generalized pronunciation.

Whereas, the learners more exposed in English speaking countries would be exceptions to that rule. It can be said that Bengali has a substantial influence on the production of English.

\section{Epenthesis}

Epenthesis mostly occurs in the beginning consonant clusters in terms of the Bengali speakers' pronunciation of English words. It may also occur in the final clusters, for instance:

\begin{tabular}{|lll|}
\hline British RP & Bfrok/ & Bengali \\
Frok & $/$ brek/ & /forok/ \\
Break & /flat/ & /ferek/ $/$ or /felat/ \\
Film & $/$ spein/ & /ispen/ \\
Spain & /sləu/ & /solo/ \\
Slow &
\end{tabular}

The above data was collected from 20-day workers in a local factory, 12 male and 8 female participants. The participants, most of whom finished their primary education and a few high school graduations, were asked to pronounce the words listed above, and most of whom came up with Epenthesis.

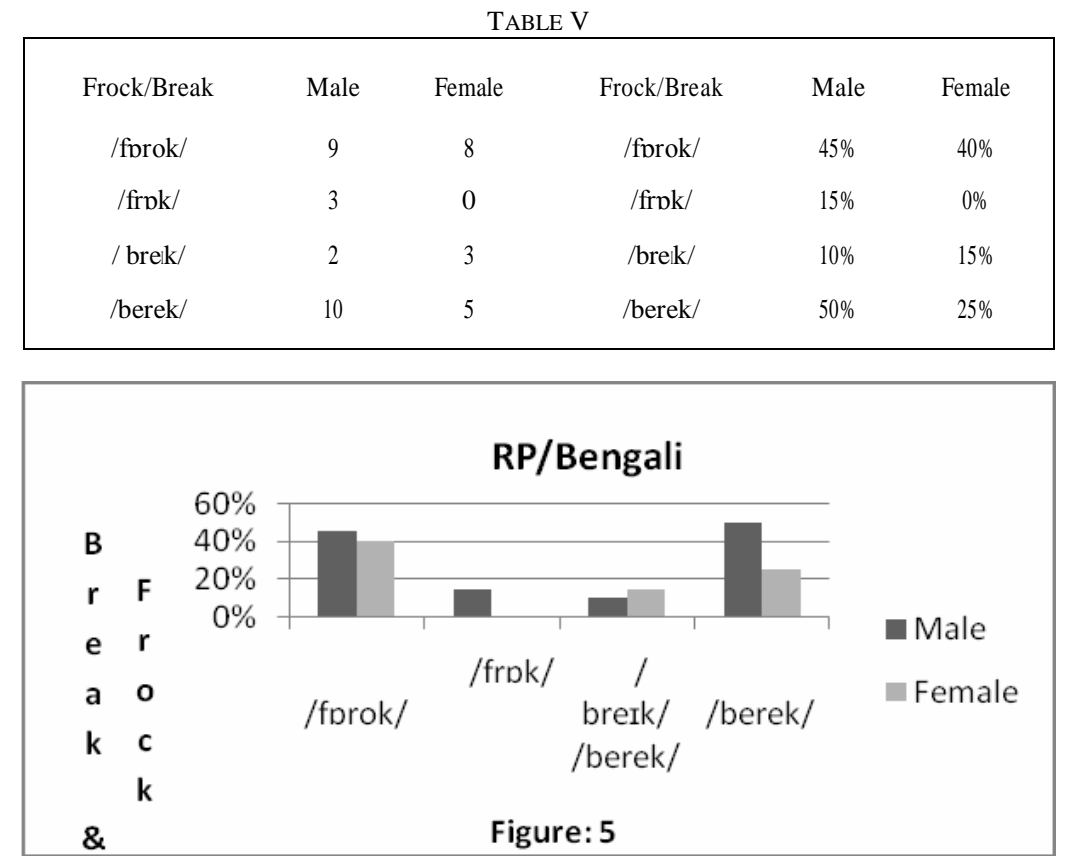

Findings: Figure: 5displayes the percentage of male and female participants who were able to pronounce the given word properly and who were not. $45 \%$ male while $40 \%$ female pronounced the word with epenthesis; similarly, $50 \%$ male and $25 \%$ female were unable to pronounce the word break. Remarkably though $10 \%$ male and $15 \%$ male could come up with proper pronunciation with varied accents. The difficulty is due to lack of practice and learning pronunciation. It can also be alluded to their lack of exposure and conversation with native speakers.

Odlin points out phonemic difference, segmental errors, (errors relating to vowels and consonants), supra-segmental errors in connection with stress, tone, rhythm and other factors. According to his understanding, stress patterns are significant for a L1 speaker to learn L2 sound systems as they affect syllables and the segments that constitute certain nouns and verbs such between COMbine and comBINE (Odlin, 1989, p. 116). Thereupon, he concludes that if stress pattern of the target language is not maintained properly in the speech, it may well create confusion and misperception of pronunciation (1989, p. 116). Odlin also discusses Bansal's (1976) opinion about the use of English in India where unintelligibility and misunderstanding mostly occur because of errors made in the stress patterns of the pronunciation in English. Considering all of these issues, a comparison between Bengali and English is made in terms of initial clusters, aspirated and non-aspirated sounds etc.

Throughout the learning process of any second language, learners' use of their native language helps as cognitive activities towards the second language. J. James believes that equivalence between L1 and L2 does not depend on 
linguists' definition of it and he focuses on learner's autonomy and he points out that:

"It is not only relevant whether L1 and L2 actually differ or are the same at a particular point or not but rather whether the learner expects or believes this to be the case. It is the learner's attitude and expectation that determines transfer or generalization within L2" (1977, p. 12).

But, Sajavaara believes that language learning taking place only before early puberty phase is 'unconscious'; and after it is very much 'conscious'... (Sajavaara in Sharwood Smith and Kellerman, 1986, p. 68). But, in this case, the deviation in diversion in pronunciation within adult Bengali speakers of English may not be conscious, but it cannot be said that 'the person cannot articulate sounds, but that they do not conceptualize them appropriately' (Nowicki, 2001, p. 17-32). Nowicki's comment is apparently worthwhile considering for the period when the learning of phonetics involves cognitive interference at post-puberty phase, whereas the problems with the sounds $/ 3: /, / d z /$ and $/ \mathrm{t} /$ would be more conspicuous on puberty.

\section{Problematics of Starndard form and Alterations: Setting Model Pedagogy to Rectify the Bengali SPEAKERS' UNINTELLIGIBILITY}

The formation of discussion on the setting of a standard form to British or American pronunciation is no longer accepted with full consent; rather the non-native teachers along with a number of researchers have found that the socalled standard form has undergone significant changes whereas non-native teachers' talk relates to the ownership of English or its pronunciation. Up until now, the aim of learning English for those to whom English has an internal significance and use in their L1 country or those who moved to English speaking countries is to communicate message in English with standard pronunciation: to achieve this goal it was considered for these 'non-native speakers' to try to make their pronunciation like the native, Received Pronunciation (RP). Yet, David Crystal believes that:

"Less than three per cent of the British population speaks RP in its pure form, with many educated people having developed an accent known as modified RP-a combination of RP and regional features" (Crystal, 1995 in Jenkins, 2000 , p. 14).

On the other hand, Daniels refers to RP speakers as the phantom speakers of English because of the impossibility of a learner coming into contact with one of them (Daniels, 1995 in Jenkins, 2000, p. 14). Though the ownership of English ${ }^{3}$ has come under question in recent years it is debatable that English cannot belong to any other nationalities other than those for whom English is their first language: there is a point in saying so as many like Kramsch is very concerned about the fact and put violent remarks:

"...They can never become native speakers of it. Why should they disregard their unique multilingual perspective on the foreign language and on its literature and culture to emulate the idealized monolingual speaker?" (Kramsch 1997, p. 359 in Jenkins)

In fact, Kramsch's remark apparently implies to the other ${ }^{4}$ not to try being native- like in pronunciation and in spoken proficiency. Nayar calls this paradigm of non-native speakers and the utilitarian ownership of English is politically pernicious, and he believes this is a linguistic imperialism (1994, p. 5). This kind of remark is countered by many like Liu Dailin saying English is England's language but the world's treasure (EL Gazette, 1996 in Jenkins, 2000, p. 5). Dailin's comment implicates the validation of world-English varieties and their pronunciation other than RP. Particularly, the dismantling of British empire in ESL countries in Indian sub-continent tend to accept and develop a range of local English accents from speakers of different L1s such as Bengali and Punjabi on one hand and are concerned to retain intelligibility on the other. This paper agrees with Bansal whose findings in India matches Bangladesh and other Bangla speaking regions that:

"The view that the only suitable model is British RP is not shared by all educated people in the country and ...it is felt that some reasonable standard should be insisted upon to ensure effective communication" (1990, p. 229-30).

Of course, Bansal's proposition is true though it is impossible to set a transformed dichotomy other than existing standard RP or General American English (GA). But, Bansal does not clarify what he means by some reasonable standard. If Bansal's proposition matches with Widdowson's neutral medium, it will be a failure:

"An entirely neutral medium for the conveyance of information is doomed to failure because as soon as the human factor intrudes, the language grows, changes, varies, becomes subject to the identifying need of speakers to express their own identity" (1982, p.11-12).

So, the choice of one standard phonetics model and its acceptance and rejection requires to delve into the fiction ${ }^{5}$ and facts related to the background of non-native speakers and it entails more empirical study other than this small effort. However, it is manifest that some L2 speakers genuinely do desire to acquire an RP accent and many more admit to preferring to retain something of their L1 accent (Porter \& Garvin, 1989 in Jenkins, 2000, p.16). Again, Benson finds

\footnotetext{
${ }^{3}$ The ownership of English has changed the notion of ESL and EIL and EFL pedagogy widely. As the debate involves talk on the ow nership of English, it delimits the study of what should be the standard model for teaching pronunciation. Despite this fact, there should be a more intelligible standard which has to be the criterion for all learners.

${ }^{4}$ This has a strong implication to the ownership of English, which again requires RP to be the standard phonetic pedagogy.

${ }^{5}$ The fiction is the most important fact to look into as most of the problems which the Bengali speakers face is due to lack of interest in trying to pronounce them correctly, not only the Bengali speakers but also other learners can overcome the intricacies of sounds since all of us share the same articulators to create sounds.
} 
that English with a Japanese accent is the second most preferred goal (1991, p. 34-48). Whereas, an American accent is preferred as learning goal rather than a British RP (Benson et al. 1994 in Jenkins, 2000, p. 16). This is obvious that learners do have a propensity to take over RP or American, and it can be argued that a model should be set in the pedagogical framework since it may be confusing for learners to determine which pronunciation to adopt. But, there cannot be any obligation on either side, so the intelligibility would be plausible in terms of the production of the sounds.

As Bengali is very rich in alphabet and their consonantal clusters, the Bengali speakers face very little problems which can be easily overcome without having to set any rigid standard pedagogy, rather they need repetition and practice for that. So, this paper agrees that 'the problem of labio-dental fricatives /f/ and /v/ can be overcome by an L1 transfer, which will not impair intelligibility' (Jenkins, 2000, p.101). This can be made identified with any local dialect pronunciation depending upon the speakers' home town. For instance, for a Chittagonian, the closest type of pronunciation with /v/ can be replaced by /vap/, a local lexis, which means smoke or evaporation in English. So, the prescription would be to do replacements with L1 equivalents to make it sound much easier and more contextual. Along with this, the mooted one to one correspondence like, /dz/and/z/and/3:/ and /a/ can be teachable to Bengali speakers to minimize ambiguity of sounds. Moreover, the epenthesis, as Jenkins (2000) believes, which corresponds to the problem of Arabic learners is a common tendency of L1 child acquisition. This problem is in all likelihood can be removed through the consonant clusters used in Bangla language, as Bangla is very rich in consonant-clusters.

\section{CONCLUSION}

Teaching the most plausible sounds to Bengali speakers of English has been the key issue throughout this paper though there must be a dichotomy in the pedagogical system as English can be entitled with two denominations in Bangladesh, ESL and EFL. Whereas, the researchers suggest; (Jenkins and Kenworthy, 1998) cloning and; (Daniels, 1995 in Jenkins) L1 regional variety, Bhatia's proposition seems to be more appropriate for any ESL or EFL student learners including Bengali speakers of English:

"...It is necessary to recognize nativized norms for international functions within specific speech communities, and then to build a norm for international use on such models, rather than enforcing or creating a different norm in addition to that" (1997, p.318).

Yet, the modification of sounds entails practice and proper instructions for Bengali speakers of English.

\section{REFERENCES}

[1] Bansal, R.K. (1990). 'The pronunciation in India' in S. Ramsaran (ed.) Studies in the pronunciation of English: A Commemorative volume in honor of A.C Gimson. London:Routledge

[2] Benson, M. (1991). 'Attitudes and motivation towards English: A survey of Japanese freshmen.' RELC Journal, Vol. 22 (1), p. $34-48$

[3] Bhatia, V.K. (1997). 'Introduction: genre analysis and world Englishes' World Englishes, Vol. 16 (3). p. 313-9

[4] Gass, S. \&Selinker, L. (1994). 'Introduction: Language transfer in language learning' in S. Gass and L. Selinker (ed.), John Benjamin's: Amsterdam/Philadelphia

[5] James, J. (1977) 'Language transfer reconsidered.' Interlanguage studies bulletin, Vol..2 (3), PP.7- 21.

[6] James, C. (1980). Contrastive Analysis, London: Longman.

[7] Jenkins, Jennifer. (2000). The Phonology of English as an international language, Oxford: Oxford University Press

[8] Karim, Khaled. (2010). Working papers of the linguistics circle of the university of victoria 20, 26-36, available on <http://grammar.about.com/od/e/g/Epenthesis.htm. retrieved November 12. 2011>.

[9] Nayar, P. B. (1994). 'Whose English is it?' TESL-EJ 1.1, F-1.

[10] Odlin, Terence. (1989). Language transfer, Cambridge University Press: Cambridge.

[11] Widdowson, H.G. (1982). 'What do we mean by "international language"?' in C.J. Brumfit (ed.) English for international communication.1st ed. Oxford; New York : Pergamon Press.

Md Nurul Anwar, author of the article, is lecturer in English at BGMEA University of Fashion and Technology, Dhaka, Bangladesh. He was educated both in Bangladesh and abroad. His research focuses on applied linguistics, language and politics in English language teaching world, phonetics and phonology, poetry and theory. He has published five articles in these areas in different International Peer-reviewed Journals as well as a book. 